\title{
Baby Boomers' Expectations of Health and Medicine
}

\author{
Eva Kahana, PhD and Boaz Kahana, PhD
}

\begin{abstract}
In the early 2010s, the first cadre of baby boomers, born after World War II, turned 65, making them officially senior citizens, and many more are joining their ranks every day. It is generally acknowledged that the entry of the baby boomers into the ranks of elderly consumers of health care is likely to create major challenges. As large numbers of baby boomers cross into old age, there will be greater demands for chronic health care and for meeting the special needs posed by the "graying of disability"-people with disabilities living longer than they did in centuries past. The coming changes in health care needs are generally conceptualized in terms of increasing demand and need for responsiveness by overburdened health care professionals [1].
\end{abstract}

\section{Involvement and Assertiveness}

But acknowledging only the growing demand for care and the inadequacy of our current system to meet it ignores the advantages of having a new breed of elderly patients. Baby boomers are different from the generations that preceded them; they are more savvy, assertive, health-conscious, and engaged in their care [2,3]. Even recently, the literature of medical sociology has portrayed older adults as reluctant to speak up to their doctors and passive in communicating about their health care $[4,5]$. Consequently, the focus of patientcentered medicine has been on training physicians to draw out shy and reticent elderly patients and provide them with more thorough information about their health care options [6].

Our recent research has involved interventions to encourage older adults to be more proactive in communicating with their clinicians [7]. As part of a randomized controlled trial (RCT), we are evaluating the efficacy of a patient communication intervention- "Speak Up" - compared to a civic engagement-oriented attention control group_- "Connect." During the four-year period of this study, we have noticed a marked increase in patient preparedness and initiatives and an increasingly active group process in which study participants offer advice to one another about speaking up to their primary care physicians and requesting test results and other data about their health status and care needs [7]. Indeed, longitudinal studies of successful aging [8] have revealed important changes in health care consumers' expectations, involvement in their own health care, and competence in navigating the health care system. Baby boomers are among the most avid consumers of health information and approach their health care providers with far greater initiative and than did older adults of

\section{Related in VM}

Consumerism in Health Care: Challenges and Opportunities, November 2013

Should Age Be a Basis for the Rationing of Health Care? May 2014 
yesteryear [9]. Baby boomers value and pursue social engagement and healthy lifestyle behaviors and have high expectations for wellness and independence in late life [10].

Members of the baby boomer generation are also playing a growing role in long-term care of the oldest old [11]. Growing numbers of them are caregivers to their parents. People are living longer and have smaller families, demographic trends that have created new demands on their baby boomer children [12]. As caregivers who are themselves dealing with the chronic illnesses of later life, boomers can serve as more understanding health care advocates.

There are important implications of this sea change in patient involvement in health care among baby boomers reaching old age. Physicians must now be prepared to interact with older patients in the same way they interact with younger patients, engaging in a more egalitarian dialogue and involving patients more earnestly in decision making.

\section{Independence}

Older patients of the present and future expect to live more active lives and seek to remain socially engaged, even as they manage chronic illnesses or rehabilitation from disabling health conditions. This generation of self-determining patients is likely to question established principles of medical care, demanding greater attention to their own definitions of health-related quality of life [13]. This is a fundamental move away from the traditional positivistic medical outcome criteria in the direction of "the new subjective medicine" that recognizes and seeks to enhance subjective criteria for health outcomes [14]. Recognition by physicians of the importance of patient values, expectations, and subjective appraisals of health and quality of life can facilitate better communication and shared decision making.

It has been recognized that ageism often limits the choices of older adults regarding longterm care [15]. While there have been meaningful efforts to offer young patients long-term care options that allow maximum control of care received and choice of caregivers, options for elderly patients with disabilities have been far more restrictive. If the new elderly place a higher premium on self-reliance, they may be eager to consider long-term residential options that facilitate independence. Our study of successful aging reveals that, among older adults who retire to Sunbelt retirement communities, those who enter continuing care living facilities maintain independence for a long time, even with multiple comorbidities [16]. Options of this kind, which promote choice and do not necessitate moving to be near other family members, may be particularly popular with baby boomers.

\section{Technology}

The elderly patients of today use the technological resources of the Internet [17]. Our smartphone-toting baby boomers carry great resources along with great expectations, literally at their fingertips. Mobile phones can enable the majority of older adults to access diverse health interventions, ranging from education to health monitoring, and health promotion. This can facilitate patients' sense of agency and self-efficacy about improving their own health [18]. Technology can play an important role in making it possible for older adults to "age in place," and online interventions have facilitated patient empowerment [19]. 
To the extent that patients can retain control, they will happily incorporate technology into their self-care and self-monitoring routines. Accordingly, baby boomers and older adults have shown similar levels of acceptance of monitoring technology as long as doing so facilitates independent living [20]. But clinicians must be sensitive to the wishes of baby boomers and older adults who may not desire externally imposed health and safety monitoring that they view as an invasion of their privacy [21]. For example, our research revealed that very few independently living older adults in the "wired" community of Celebration, Florida, opted to have telemonitoring of their blood glucose or blood pressure by the local health center [22].

As we consider the implications of this changing health care landscape for physicians, we have to acknowledge that doctors will continue to play a central role in that brave new world. Studies continue to confirm that patients place greatest trust in information they obtain from their physicians, but more and more older patients look for information online before they consult their physicians [23]. Consequently, physicians must embrace technology in meaningful, rather than pro forma, interactions with their older patients. For example, the reluctance of doctors to exchange e-mails with patients deserves a second look. There is evidence that physicians who regularly use e-mail in communicating with colleagues overwhelmingly refrain from doing so with patients [24]. Research indicates that interventions encouraging doctor-patient e-mail communication yielded positive results for both groups [25]. As baby boomers seek efficient and timely communication with physicians to help in coping with chronic illnesses, access to e-mail communication can yield clear benefits.

Despite the possible challenges posed by baby boomers' expectations for better quality of life in their older years, the health-promoting lifestyles they have embraced and popularized will pay dividends in improved health outcomes and reduced burdens for the physicians treating them. Indeed, it has been argued that interest in active lifestyles and healthy diets by baby boomers is fueling the wellness revolution in our society [2]. It is well recognized that health-promoting lifestyles can delay the onset of chronic illnesses and diminish dependence on health care services [26]. And the future may also hold as-yet unheralded medical advances that will benefit these patients as well as their doctors.

\section{Acknowledgments}

The viewpoints expressed on this site are those of the authors and do not necessarily reflect the views and policies of the AMA.

\section{Biographies}

Eva Kahana, PhD, is Robson Professor of the Humanities; Distinguished University Professor in sociology, nursing, medicine, and applied social sciences; and director of the Elderly Care Research Center at Case Western Reserve University in Cleveland, Ohio. She has published more than 170 journal articles and book chapters, co-authored four books, and edited three volumes. An underlying theme in Kahana's scholarship is the understanding of resilience among elderly persons who encountered stress and trauma in their lives, particularly Holocaust survivors, cancer survivors, and institutionalized elderly people. She 
has received numerous awards, including the Distinguished Career Contribution Award and the Lawton Award from the Gerontological Society of America.

Boaz Kahana, $\mathrm{PhD}$, is a professor of psychology at Cleveland State University in Ohio, where he has served as chair of the Department of Psychology. Professor Kahana's research has focused on trauma survivorship among veterans, Holocaust survivors, and cancer survivors. He has more than 140 refereed publications including authorship of the 2005 book Holocaust Survivors and Immigrants: Late Life Adaptation. He is a fellow of the American Psychological Society and of the Gerontological Society of America and has served on the editorial boards of several gerontology journals, most recently the Journal of Mental Health and Aging. He has received, among other honors, the Arnold Heller Award for Excellence in Gerontology.

\section{References}

1. Kahana E, Kahana B. On being a proactive health care consumer: making an "unresponsive" system work for you. Res Sociol Health Care. 2001; 19:21-44.

2. Kickbusch I, Payne L. Twenty-first century health promotion: the public health revolution meets the wellness revolution. Health Promot Int. 2003; 18(4):275-278. [PubMed: 14695358]

3. Wilson, LB. Civic Engagement and the Baby Boomer Generation: Research, Policy, and Practice Perspectives. Binghamton, NY: Haworth/Psychology Press; 2006.

4. Ekdahl AW, Andersson L, Friedrichsen M. "They do what they think is the best for me." Frail elderly patients' preferences for participation in their care during hospitalization. Patient Educ Couns. 2010; 80:233-240. [PubMed: 19945814]

5. Kahana E, Kahana B, Lovegreen L, Kahana J, Brown J, Kulle D. Health care consumerism and access to health care: educating elders to improve both preventive and end-of-life care. Res Sociol Health Care. 2011; 29:173-193.

6. Stewart, M. Patient-Centered Medicine: Transforming the Clinical Method. London, UK: Radcliffe Medical; 2003

7. Kahana, E., Kahana, B., Goler, T., Force, L., Siegel, J. Elderly intervention participants reflect on cancer prevention and chronic illness management. Paper presented at: American Psychosocial Oncology Society, 11th Annual Conference; February 2014; Tampa, FL.

8. Kahana E, Kelley-Moore J, Kahana B. Proactive adaptations and successful aging: a longitudinal study of stress exposure and quality of life. Aging Ment Health. 2012:1-14.

9. Cline RJ, Haynes KM. Consumer health information seeking on the Internet: the state of the art. Health Educ Res. 2001; 16(6):671-692. [PubMed: 11780707]

10. Morrow-Howell, N., Gehlert, S. Social engagement and a healthy aging society. In: Prohaska, TR.Anderson, LA., Binstock, RH., editors. Public Health for an Aging Society. Baltimore, MD: Johns Hopkins Press; 2012. p. 205

11. Robine JM, Michel JP, Herrmann FR. Who will care for the oldest people in our ageing society? BMJ. 2007; 334(7493):570-571. [PubMed: 17363829]

12. Spillman BC, Pezzin LE. Potential and active family caregivers: changing networks and the “sandwich generation". Milbank Q. 2000; 78(3):347-374. [PubMed: 11028188]

13. Kane RL, Kane RA. What older people want from long-term care, and how they can get it. Health Aff. 2001; 20(6):114-127.

14. Sullivan M. The new subjective medicine: taking the patient's point of view on health care and health. Soc Sci Med. 2003; 56(7):1595-1604. [PubMed: 12614708]

15. Lovegreen LD, Kahana E, Kahana B. Residential relocation of amenity migrants to Florida: "unpacking" post-amenity moves. J Aging Health. 2010; 22(7):1001-1028. [PubMed: 20647535]

16. Luciano JS, Cumming GP, Wilkinson MD, Kahana E. The emergent discipline of health web science. J Med Internet Res. 2013; 15(8):e166. [PubMed: 23968998] 
17. Samoocha D, Bruinvels DJ, Elbers NA, Anema JR, van der Beek AJ. Effectiveness of web-based interventions on patient empowerment: a systematic review and meta-analysis. J Med Internet Res. 2010; 12(2):e23. [PubMed: 20581001]

18. Krishna S, Boren SA, Balas EA. Healthcare via cell phones: a systematic review. Telemed J E Health. 2009; 15(3):231-240. [PubMed: 19382860]

19. Rogers WA, Fisk AD. Toward a psychological science of advanced technology design for older adults. J Gerontol Psychol Sci Soc Sci. 2010:645-653.

20. Mihailidis A, Cockburn A, Longley C, Boger J. The acceptability of home monitoring technology among community-dwelling older adults and baby boomers. Assistive Technology. 2008; 20(1):112. [PubMed: 18751575]

21. Hesse BW, Nelson DE, Kreps GL, et al. Trust and sources of health information: the impact of the Internet and its implications for health care providers: findings from the first Health Information National Trends Survey. Arch Intern Med. 2005; 165(22):2618-2624. [PubMed: 16344419]

22. Kahana, E. Using technology as a tool for successful aging. Paper presented at: Gerontechnology, Today and Tomorrow; Seattle, WA. Oct 30. 2004

23. Kahana E, Lawrence RH, Kahana B, et al. Long-term impact of preventive proactivity on quality of life of the old-old. Psychosomat Med. 2002; 64(3):382-394.

24. Forkner-Dunn J. Internet-based patient self-care: the next generation of health care delivery. J Med Internet Res. 2003; 5(2):e8. [PubMed: 12857664]

25. Leong SL, Gingrich D, Lewis PR, Mauger DT, George JH. Enhancing doctor-patient communication using email: a pilot study. J Am Bd Fam Prac. 2005; 18(3):180-188.

26. Evans RG, Stoddart GL. Producing health, consuming health care. Soc Sci Med. 1990; 31(12): 1347-1363. [PubMed: 2126895] 